LBNL-51490

SCMAG-793

\title{
The Refrigeration and Cryogenic Distribution System for the Short Pulse X-ray Source
}

\section{Michael A. Green and John N. Corlett Lawrence Berkeley National Laboratory Berkeley CA 94720}

\section{The Refrigeration and Cryogenic Distribution System}

This report describes the essential elements of the cryogenic system. The cryogenic distribution system starts at the level of the linac superconducting RF cavities [1] and moves out through the cryogenic piping to the liquid helium refrigeration plant that will be used to cool the RF cavities and the undulator magnets. For this report, the cryogenic distribution system and cryogenic refrigerator includes the following elements:

1) The piping within the linac cryogenic modules will influence the heat transfer through the super-fluid helium from the outer surface of the TESLA niobium cavity and the liquid to gas interface within the horizontal header pipe where the superfluid helium boils. This piping determines the final design of the linac cryogenic module.

2) The acceptable pressure drops determine the supply and return piping dimensions.

3) The helium distribution system is determined by the need to cool down and warm up the various elements in the light source.

4) The size of the cryogenic plant is determined by the heat loads and the probable margin of error on those heat loads. Since the final heat loads are determined by the acceleration gradient in the cavities, a linac with five cryogenic modules will be compared to a linac with only four cryogenic modules.

The design assumes that all cryogenic elements in the facility will be cooled using a common cryogenic plant. To minimize vibration effects on the beam lines, this plant is assumed to be located some distance from the synchrotron light beam lines. All of the cryogenic elements in the facility will be attached to the helium refrigeration system through cryogenic transfer lines. The largest single cryogenic load is the main linac, which consists of four or five cryogenic modules depending on the design gradient for the cavities in the linac section. The second largest heat load comes from the cryogenic 
modules that contain the transverse deflecting RF cavities. The injector linac is the third largest heat load. The seven superconducting undulator magnets in the hard x-ray production section are the smallest heat loads connected to the light source refrigeration plant. The linac and deflecting cavity sections require helium cooling at $1.9 \mathrm{~K}, 5 \mathrm{~K}$ and 40 $\mathrm{K}$. The undulator magnets require two-phase helium cooling at 4.3 to $4.5 \mathrm{~K}$

\section{TESLA Cryogenic Module Modifications Needed to Improve Cavity Cooling}

The TESLA cavities have been demonstrated to operate routinely at gradient above 25 MV per meter, and tests at the DESY test facility have shown operations above $35 \mathrm{MV}$ per meter in some cavities [1]. We propose to operate the superconducting cavities in CW mode to allow $10 \mathrm{kHz}$ bunch repetition rate, as opposed to the $0.7 \%$ duty factor of the TESLA design, resulting in significantly larger heat loads. A nine-cell cavity operating in $\mathrm{CW}$ mode at $25 \mathrm{MV}$ per meter will have $63.5 \mathrm{~W}$ heat generated as a result of RF current flow on the inner surface of the cavity. Added to this is $8.5 \mathrm{~W}$ heat entering the cavity niobium body from the input RF power coupler. This dynamic heat load is to be transferred through the niobium to the cavity outer surface in the super-fluid helium liquid bath, then to the super-fluid helium surface where boiling occurs at $1.8 \mathrm{~K}$, without quenching the cavity. In a super-fluid helium test bath there is no problem transferring this heat from the cavity outer surface to the super-fluid helium surface, however, the transport of about $72 \mathrm{~W}$ from the cavity outer surface through the helium tank, the feed-pipe and the header-pipe configuration proposed for the TESLA cryogenic modules will require some modifications.

With modifications to the helium tank, helium feed pipe and the helium header pipe the transport of heat within the TESLA cavity cryogenic module is not a problem. The heat transfer from the cavity surface to the liquid helium surface is limited by the heat transfer area in the tank (the area of between the cavity convolutions and the cavity helium tank wall), the total area of the helium feed pipe or pipes, and the area of the cross-sectional area of liquid helium that is in the feed pipe. In general, the heat transfer limit for the liquid super-fluid helium in the tank, the feed pipe and the header is about 0.6 to $0.7 \mathrm{Wcm}^{-2}$ [2]. In TESLA, the area of the space between the cavity convolutions and the tank is about $40 \mathrm{~cm}^{2}$. The area of the feed pipe between the header and the tank is $28 \mathrm{~cm}^{-2}$. The crosssectional area of the liquid in a half-full header pipe is about $20 \mathrm{~cm}^{-2}$. 
In order provide sufficient heat transfer from the cavity outer surface to the surface of the liquid in the header, the following modifications to the basic TESLA cryogenic module design are recommended:

1) The number of feed pipes between the RF cavity helium tank and the two-phase helium standpipe should be increased from one to two.

2) The helium feeds should enter the helium tank at near the ends so heat can flow two ways along the RF cavity. If one puts the feeds at the one-quarter and three-quarter points along the cavity, the flow along the cavity is split four ways, and cavity cool down is not as effective.

3) The inside diameter of the helium tank should be increased by 10 to $15 \mathrm{~mm}$ to increase the spacing between the cavity convolutions and the cavity helium tank inner wall.

4) The liquid helium feed pipes from the standpipe to the tank should have their inside diameter increased from $60 \mathrm{~mm}$ to $100 \mathrm{~mm}$ (so that the effective inside area of the pipe is at least $78 \mathrm{~cm}^{2}$ ).

5) The two-phase helium header pipe should have its inside diameter increased from $70 \mathrm{~mm}$ to $100 \mathrm{~mm}$ to allow heat to flow through the liquid in a half full pipe.

If one does all of these things, the heat flow through the super-fluid helium in the tank and the pipes will less than $0.45 \mathrm{~W} \mathrm{~cm}^{-2}$ in all of the liquid helium spaces. Figure 1 shows a cross-section view of the proposed modified TESLA cryogenic module. If the proposed changes do not fit into the standard TESLA cryogenic module cryostat vacuum vessel, the diameter of the 300-mm helium gas return pipe can be reduced to the next standard pipe size with an inside diameter greater than $250 \mathrm{~mm}$. 


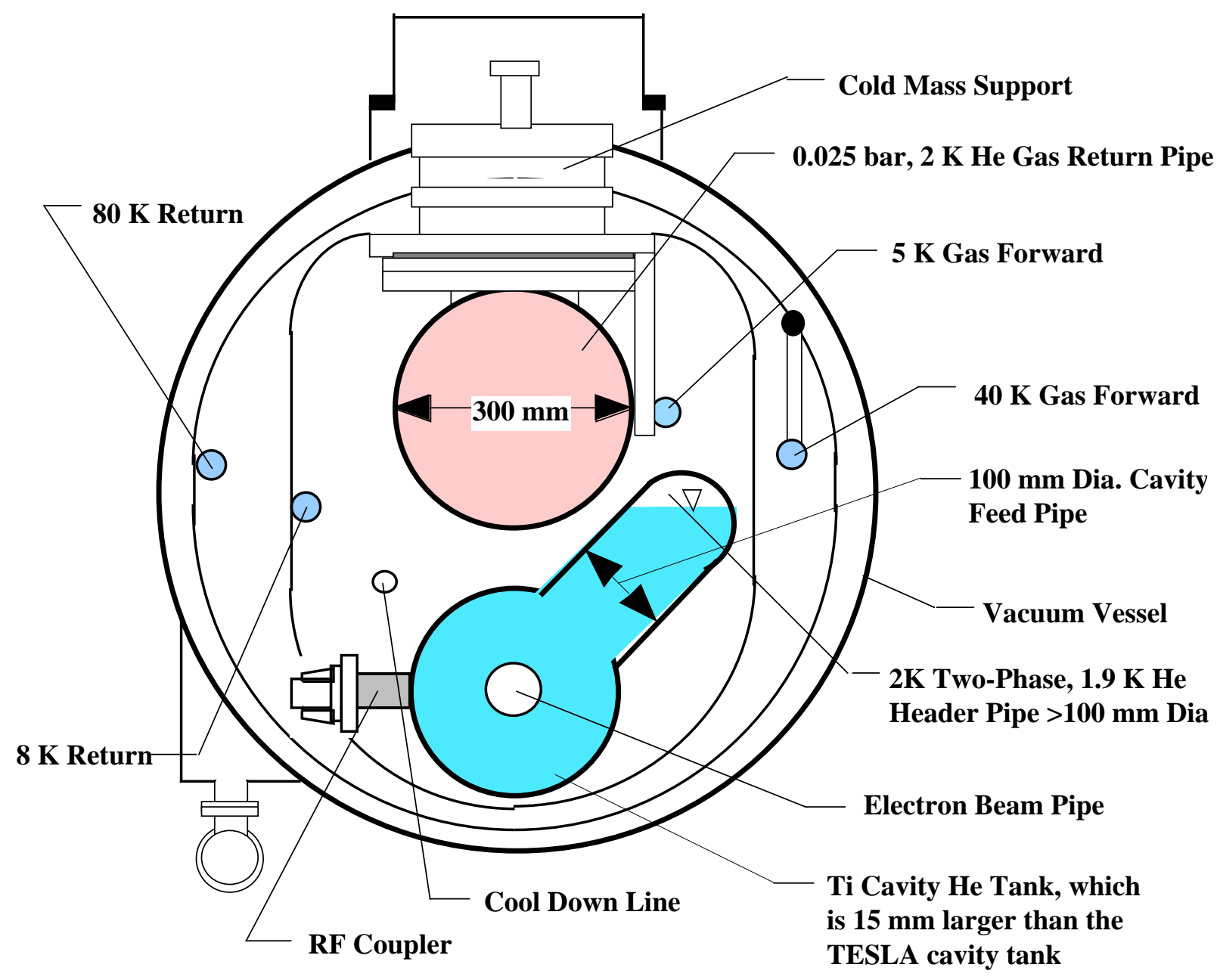

Figure 1. A cross-section of the proposed modified TESLA cryogenic module for the Sort pulse Light Source Linac. The cryogenic module above looks like a TESLA module, but key dimensions are increased in the tank, the header pipe, and the standpipe to accommodate the added CW heat load. 


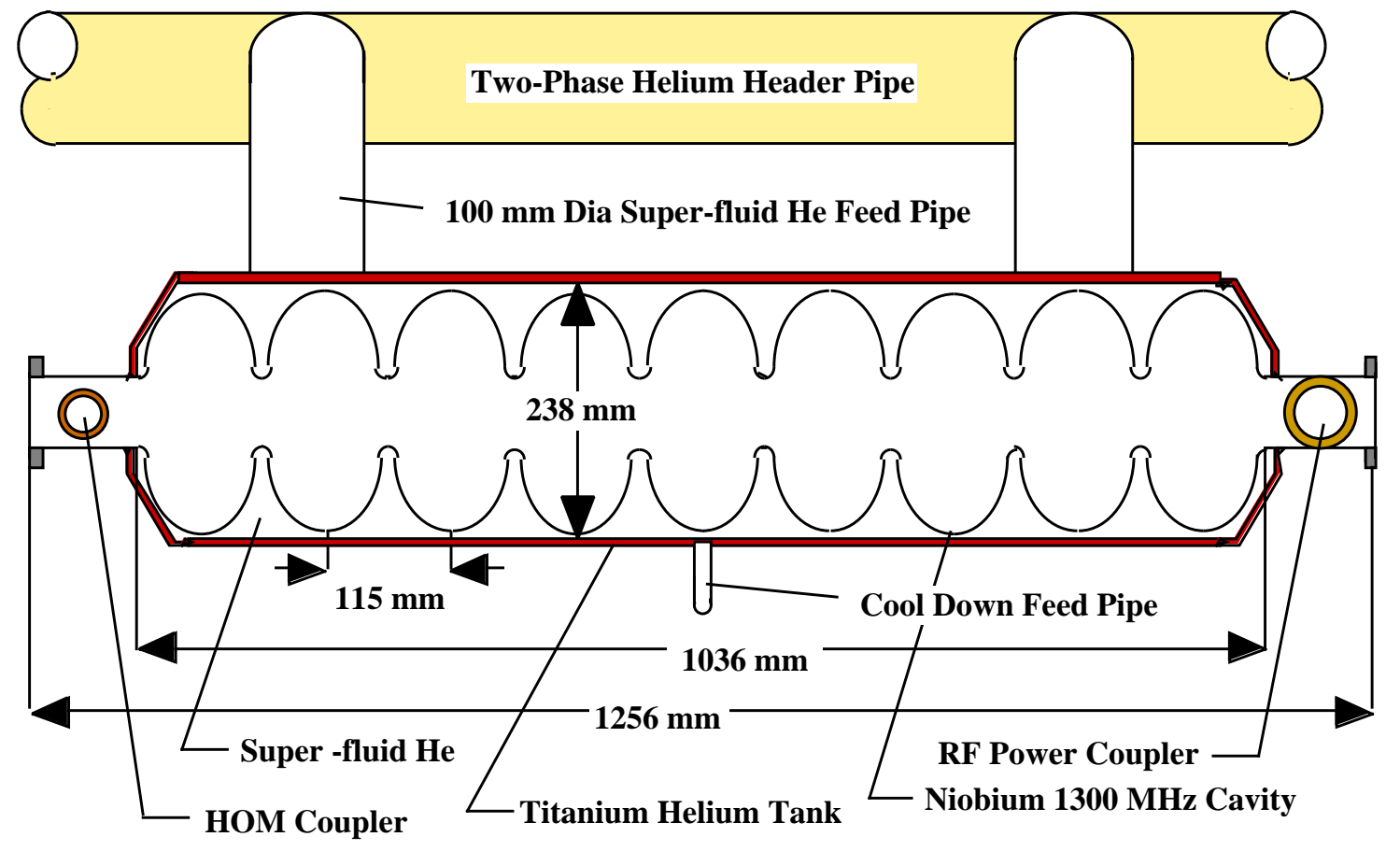

Figure 2. A Cross-section view of the increased diameter TESLA cavity helium tank, super-fluid helium feed pipes, and the two-phase helium header

\section{Cryogenic Module Piping and Transfer Lines to the Cold Box}

As with the TESLA design, the linac cryogenic modules will be used as part of the helium transport system to and from the 1.8 to $1.9 \mathrm{~K}$ refrigerator (see Figures 1 and 2 ). The most important transfer line in the entire cryogenic module is the return line that carries $1.9 \mathrm{~K}$ helium back to the refrigerator cold box, since the pressure drop in this transfer line determines the operating temperature of the RF cavities. Helium gas in equilibrium with liquid helium at $2.0 \mathrm{~K}$ is at a pressure of 0.0313 bar ( $23.5 \mathrm{torr}$ ). If the helium is at $1.8 \mathrm{~K}$, the saturation pressure drops to 0.0164 bar (12.3 torr). Helium in this range of temperature and pressure is an ideal gas with very low density, and as a result the helium volume flow through the return pipe must be high.

The pressure drop in the return line not only determines the pressure and temperature in the cavity helium tank, but it also determines the operating temperature of the cryogenic system cold box if the cavities operate below the lambda transition temperature of $2.176 \mathrm{~K}$. Since the excellent thermal conductivity of super-fluid helium is an integral part of 
removing the heat from the RF cavities, the operating temperature of the cavities can not be more than about $2.0 \mathrm{~K}$. Since the pressure drop along a pipe carrying gas in turbulent flow is proportional to the pipe length, proportional to the gas mass flow rate squared, and inversely proportional to the pipe inside diameter to the 4.8 power, we find that for given length of return line and mass flow one can get the desired pressure drop by increasing the pipe diameter. If the cavity operating temperature is set at $2.0 \mathrm{~K}$, a reduction of the return pipe size means that the cold box must operate at a lower temperature. A lower temperature cold box requires more input power to the compressors and is more expensive. In short, there is an optimum diameter for the $1.9 \mathrm{~K}$ return line to the cold box of about 250 $\mathrm{mm}$ for the proposed facility cryogenic system operating at $2 \mathrm{~K}$. (See Figure 3.) The TESLA design 300-mm return pipe shown in Figure 1 is just about the correct size. Because, the helium gas flow per TESLA cavity is increased by an order of magnitude, there must be frequent interconnect between the header pipe and the $1.9 \mathrm{~K}$ return.

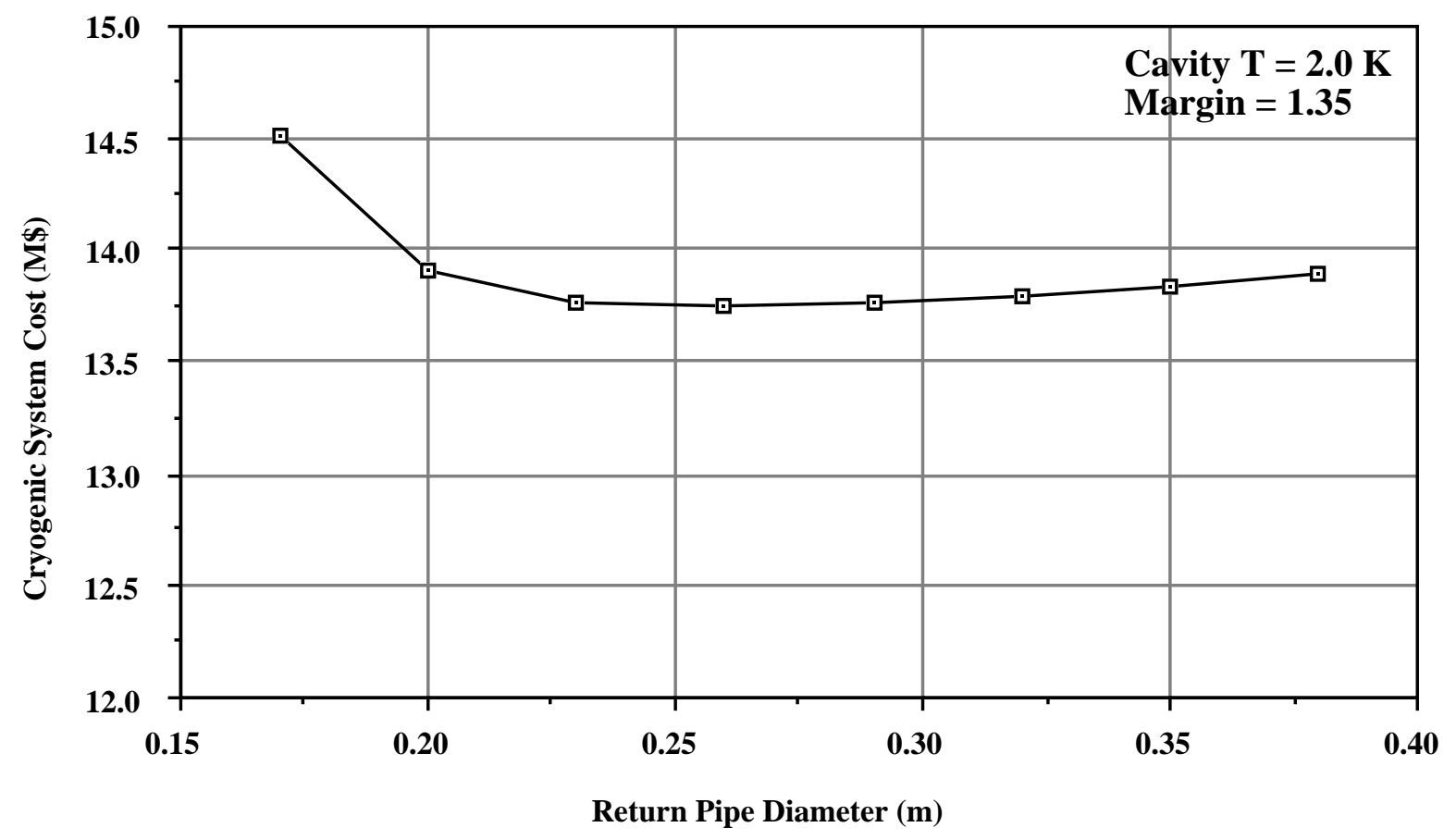

Figure 3. Refrigeration system cost versus the diameter of the $1.9 \mathrm{~K}$ helium return pipe. (The cold box is sized 35 percent larger than the calculated heat load.) 
The optimization of the return line was performed for a number of cavity loads and refrigeration operating margins, and in no case was the optimum helium return line diameter less than $240 \mathrm{~mm}$. As one can see from Figure 3, the optimum is rather broad. The 300-mm diameter pipe shown in Figure 1 seems to be a reasonable size that allows for extra line length and increased heat loads.

The two-phase helium header pipe shown in Figures 1 and 2 serves as the cryogenic supply line for the superconducting linac and is sized for heat transfer in the super-fluid helium. The pressure drop along this line during normal operation is quite low as long as the boil off gas is taken from the two-phase helium header and fed to the cold helium return pipe. This gas should be taken off at about every cavity in the cryogenic module. The header extends from one cryogenic module to the next, and the cold helium gas return pipe also extends down the length of the linac from one cryogenic module to the next.

The cool down pipe shown in Figure 2 is sized to allow the cavities to be cooled down quickly. Since dynamic (RF induced) loss is not a factor in this pipe size, the size used for the TESLA cryogenic modules is also adequate for our purposes. The cool-down pipe enters the bottom center of the cavity helium tank and the cool-down helium leaves the upper part of the tank through the super-fluid feed pipes, and is taken back to the cold box through the cold helium return pipe. During $2 \mathrm{~K}$, operation, the cool down line is filled with helium II.

Figure 4 shows a schematic representation of the flow circuit for the cryogenic modules of one of the RF sections. The circuit shown in Figure 4 applies for the main linac, the injection linac and the deflecting cavities. The line labeled the "cool down line" comes from lower end of the final expansion engine in the refrigerator cold box. The line labeled the "two-phase helium header" also comes from the final expansion turbine. The gas in this line leaves the turbine, passes through a J-T heat exchanger and through a J-T valve. The other side of the J-T heat exchanger is cooled by the $1.9 \mathrm{~K}$ gas returning from the RF cavities. 


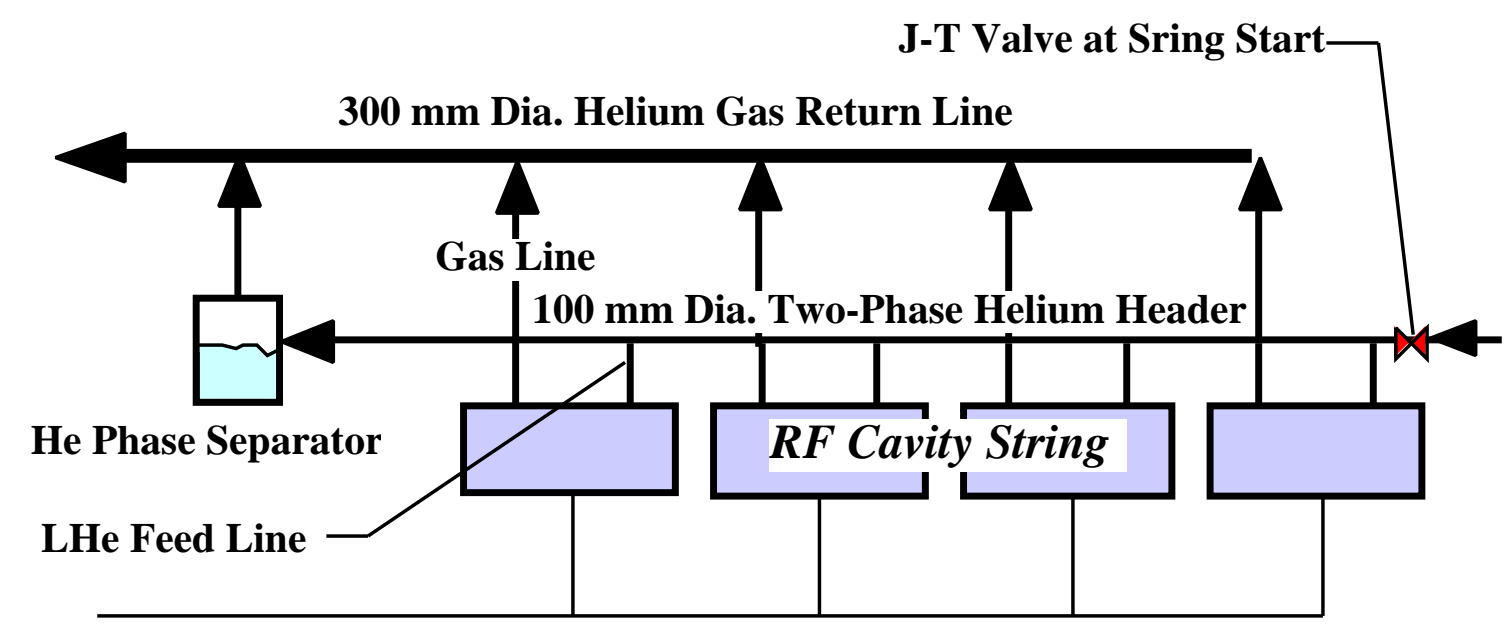

Cool Down Line

Figure 4. Simplified flow schematic diagram for the cooling of and the cool down of the RF Cavities. Note: the two-phase helium in the header comes from refrigerator cold box final J-T heat exchanger. The final J-T valve is shown at the start of the RF cavity string.

The flow circuits for the undulator magnets are different from the flow circuits for the RF cavity strings. The undulator magnets will be indirectly cooled using two-phase helium in tubes attached to the iron and coil package. The two-phase helium cooling system proposed is similar to the cooling system used for large detector magnets. The heat exchanger and phase separator causes the helium to enter the magnet string in the subcooled state. The magnets are electrically connected to the outside world through combined high temperature superconductor (HTS) leads and gas-cooled leads. The magnet shield and gas-cooled leads will be cooled by a helium stream from the $40 \mathrm{~K}$ circuit of the refrigerator cold box. This helium will pass through the shield then the gascooled leads returning to the compressor intake at $300 \mathrm{~K}$. An illustration of an undulator cooling circuit is shown in Figure 5. Note the top of the HTS leads is cooled from the gas in the cooled shield, the gas is then returned to the compressor intake at $300 \mathrm{~K}$. 


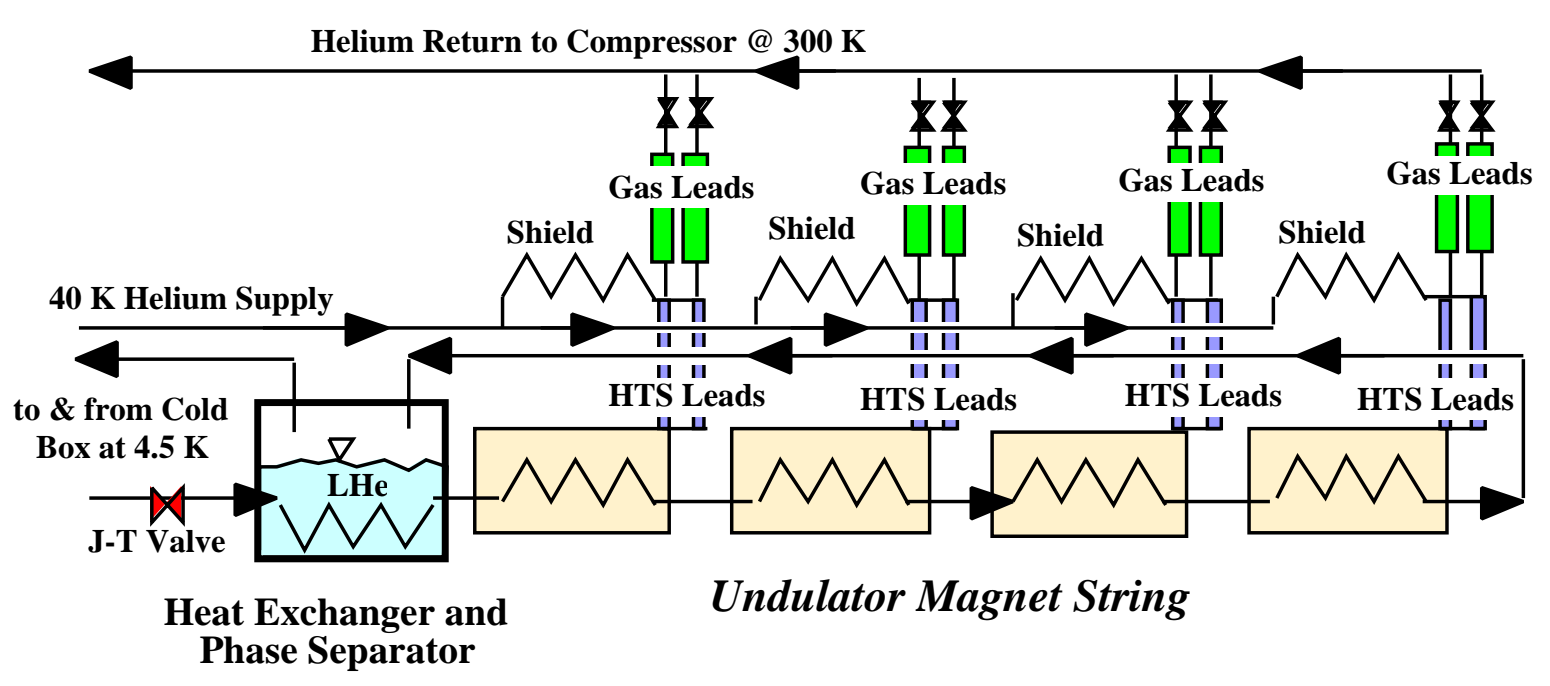

Figure 5. A flow schematic for the undulator magnet two-phase helium cooling system and the shield cooling. Note: Only four of the undulator magnets are shown. This circuit can be applied to all the magnets.

\section{The 1.9 K Helium Cold Box, Warm Compressors and Cold Compressors}

A flow schematic for a typical $1.9 \mathrm{~K}$ cold box is shown in Figure 6. The cold box consists of a warm $(300 \mathrm{~K})$ compressor station, oil separation and inter-coolers, a series of helium heat exchangers (minimum of three pass heat exchangers), several stages of expansion engines, the final expansion valves to produce $1.9 \mathrm{~K}$ liquid helium (this valve is not shown in Figure 6, but it is shown in Figure 4.), and cold compressors to compress the helium at 0.0233 bar before it goes up the heat exchanger to the first stage compressor intake [3], [4].

The compressor shown in Figure 6 is a three-stage compressor set, with low-pressure intake at 0.4 bar. The first intermediate pressure is at 1.4 bar; the second intermediate stage is at 5 bar; and the final stage is at 18 bar. The compression ratio of each stage is about 3.6. This ratio is quite typical for screw compressors used in modern helium refrigeration plants. Each stage of compression is followed by an inter-cooler to cool the helium to approximately $320 \mathrm{~K}$. After the final stage of compression an oil removal system is used to remove the oil that floods the compressors to improve cooling of the gas as it is compressed. The oil removal system and purifiers are not shown in Figure 6. 
Three Stage Screw Compressor

System with Intercooling

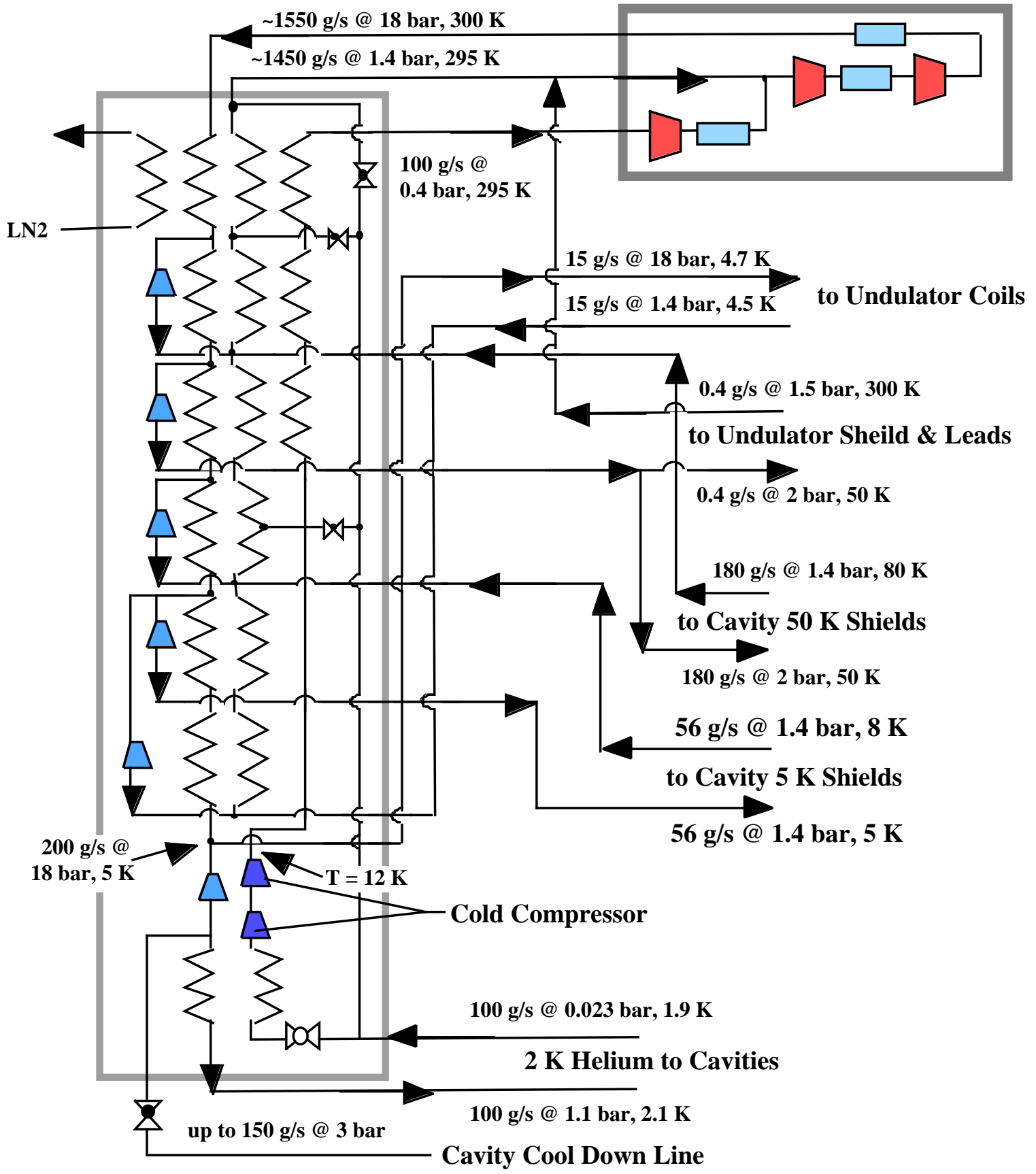

Figure 6. A flow schematic for a refrigerator cold box and its warm and cold compressors. Note: the cold box used for the $1.9 \mathrm{~K}$ refrigerator may have more than three passes in the heat exchangers, and the compressor may have more stages than are shown. A more detailed view of the cold compressor end of the refrigerator cold box is shown in Figure 7. 
This arrangement of the expanders and heat exchangers is one that has been successfully used for $1.9 \mathrm{~K}$ systems. The configuration of a modern machine may, however, be somewhat different from that shown in Figure 6, in particular the refrigerator manufacturer will likely define the turbine and expander and heat exchanger configuration to best fits the type of turbine and the thermal dynamic cycle preferred. More efficient cycles will have more stages of optimized expansion, whereas cycles with fewer expansion stages and simpler heat exchanger configurations will less expensive to build. The final configuration of the refrigeration cycle will be set by the manufacturer during the proposal and bid process based on cost and the detailed machine design parameters.

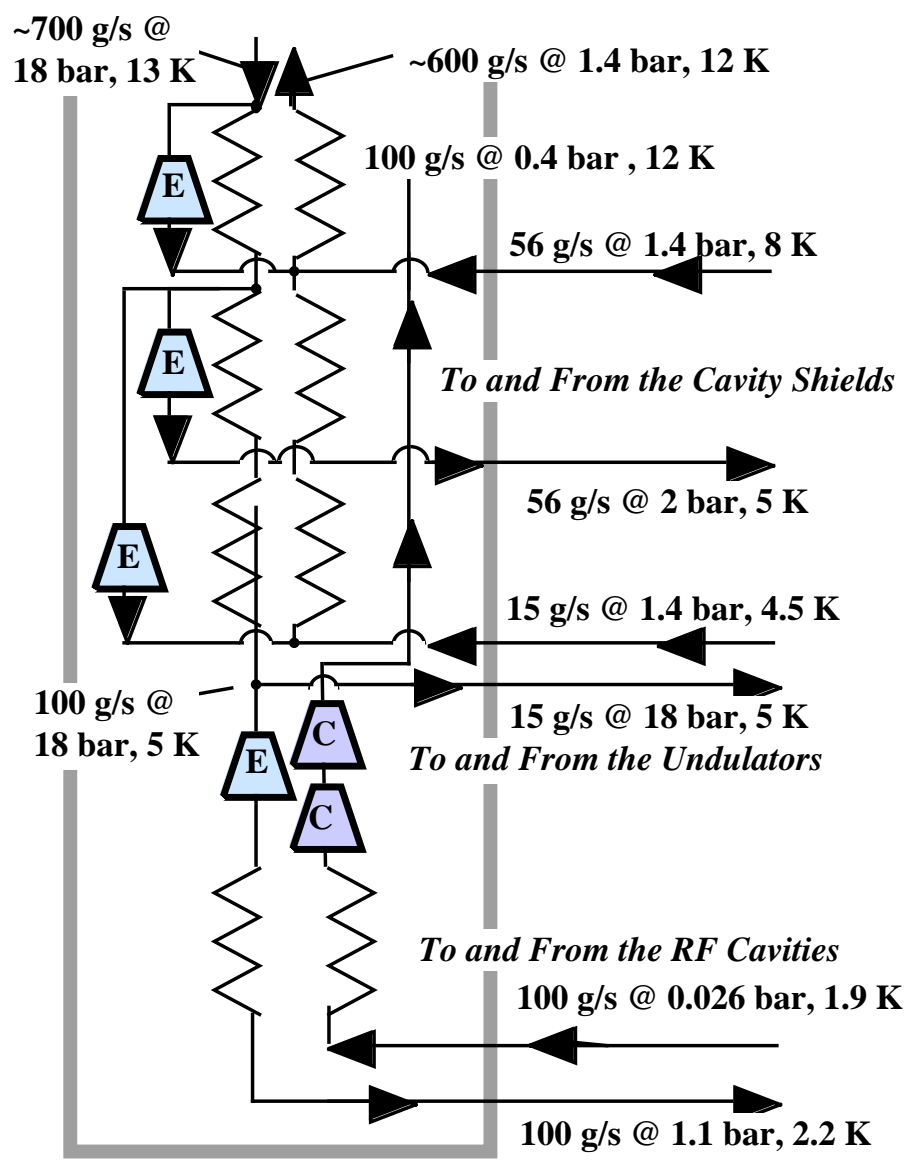

Figure 7. A flow schematic for the cold compressor end of a $1.9 \mathrm{~K}$ helium cold box Note: The rest of the cold box is shown in Figure 6. 
A key element in modern $1.9 \mathrm{~K}$ systems is a cold compressor system that compresses the cold helium coming back through the J-T heat exchanger on the return side. The use of cold compressors reduces the size of the heat exchangers on the return side of the refrigerator cold box, and eliminates the low-pressure side of the heat exchanger pressure drop as a design factor. Early systems that operated without cold compressors were limited in low temperature capacity by this pressure drop. The cold compressors shown in Figure 7 are assumed to be about 65 percent efficient, large size cold compressors may be somewhat more efficient [5]. The use of cold compressors does not significantly improve the overall efficiency of the cycle, but they do reduce the capital cost of the cold box and warm compressor system.

\section{Calculated Heat Loads and Refrigeration Cost for the Light Source}

Table 1 shows the calculated heat loads for the cryogenic components. The injector linac is assumed to have one cryogenic module with an acceleration gradient of $15 \mathrm{MV}$ per meter. The cryogenic modules containing seven deflecting cavities are assumed to have a transverse gradient of $5 \mathrm{MV}$ per meter. There are seven 2-meter long undualtor magnets that operate at $4.5 \mathrm{~K}$ in the hard $\mathrm{x}$-ray production section.

Two designs for the main linac are included in Table 1, the first assumes five cryogenic modules with eight cavities each operating at a design gradient of $20 \mathrm{MV}$ per meter, the second has four cryogenic modules with eight cavities each that operate with a design gradient of $25 \mathrm{MV}$ per meter. The higher gradient linac occupies less real estate, but the overall cost for that system might be higher. In all of the RF cavities the design $\mathrm{Q}$ value was set at $10^{10}$, although the actual average cavity in the linac may have a higher $\mathrm{Q}$ and this can dramatically reduce the dynamic loss at the cavity design operating temperature of 2.0 $\mathrm{K}$. Table 1 shows that $\mathrm{CW}$ operation of the RF systems results in heat loads at all temperatures that are dominated by dynamic losses.

The second linac also has a lower operating margin for the cavity $\mathrm{Q}$ and it has a higher temperature drop from the cavity wall to return gas. From tests of TESLA cavities at DESY, the average $Q$ of cavities operating at $25 \mathrm{MV}$ per meter is about $1.2 \times 10^{10}$. On the other hand, the average $\mathrm{Q}$ of cavities operating at $20 \mathrm{MV}$ per meter is about $1.5 \times 10^{10}$. The average $Q$ for the cavities will have an effect on the operating margin (or design heat load) chosen for the refrigeration system used to cool the cavities. For the linac operating at 20 
MV per meter, the $2 \mathrm{~K}$ design heat load chosen is the same as the calculated heat load. For the linac operating at $25 \mathrm{MV}$ per meter, the $2 \mathrm{~K}$ design heat load chosen is 1.3 times the calculated heat load. For the pre-linac cavities and the deflecting cavities the design $2 \mathrm{~K}$ heat load is the calculated heat load. For heating at all other temperatures, the design heat load is set at 1.3 times the calculated.

\section{Table 1. Calculated heat loads for various components}

Parameter

Acceleration Grad (MV/m)

No. Cryogenic Modules

No. Cavities / Module Heats Loads at $2.0 \mathrm{~K}$

AC Losses (W)

Static Heat Load (W)

Total Heat Load (W)

Heat Loads at $4.5 \mathrm{~K}$

AC Losses (W)

Static Heat Load (W)

Total Heat Load (W)

Heat Loads from $5 \mathrm{~K}$ to $8 \mathrm{~K}$

AC Losses (W)

Static Heat Load (W)

Total Heat Load (W)

Heat Loads from $40 \mathrm{~K}$ to $80 \mathrm{~K}$

AC Losses (W)

Static Heat Load (W)

Total Heat Load (W)

$\begin{array}{rcccc}\begin{array}{c}\text { Linac } \\ \text { Cavities }\end{array} & \begin{array}{c}\text { Linac } \\ \text { Cavities }\end{array} & \begin{array}{c}\text { Pre-Linac } \\ \text { Cavities }\end{array} & \begin{array}{c}\text { Transverse } \\ \text { Cavities }\end{array} & \begin{array}{c}\text { Undulator } \\ \text { Magnets }\end{array} \\ 20 & 25 & 15 & 5 & \text { NA } \\ 5 & 4 & 1 & 2 & 7 \\ 8 & 8 & 8 & 7 & \text { NA } \\ 1728.8 & 2139.6 & 198.6 & 395.1 & --- \\ 32.2 & 27.0 & 11.3 & 15.4 & --- \\ 1761.0 & 2166.6 & 209.9 & 410.5 & --- \\ & & & & \\ --- & --- & --- & --- & 0,0 \\ --- & --- & --- & --- & 157.6 \\ --- & --- & --- & --- & 157.6 \\ & & & & \\ 394.4 & 326.2 & 75.5 & 112.1 & --- \\ 99.4 & 81.9 & 29.5 & 43.0 & --- \\ 493.8 & 408.4 & 105.0 & 155.1 & --- \\ 15327.4 & 17918.5 & 1879.8 & 508.7 & 0.0 \\ 500.2 & 408.4 & 132.1 & 202.4 & 407.0 \\ 15827.6 & 18326.9 & 2011.9 & 711.1 & 407.0\end{array}$

Table 2 shows the design heat load for the entire machine at all cryogenic systems temperatures. For all cases, the design heat load is at least a factor of 1.3 higher than the calculated heat load. In the second and fourth columns of Table 2, the design heat load is converted to equivalent helium refrigeration at $4.5 \mathrm{~K}$. This allows one to calculate the size and cost of the helium plant needed. The refrigeration at $2 \mathrm{~K}$ is the largest fraction of the equivalent refrigeration at $4.5 \mathrm{~K}$, and has the largest influence on the cost of the overall refrigeration system. The cost of the refrigeration plant is proportional to the equivalent refrigeration at $4.5 \mathrm{~K}$ to the 0.7 power [6]. The cost of cryogenic system control, transfer lines, and compressor cooling is not strongly dependent on the equivalent design 
refrigeration at $4.5 \mathrm{~K}$. The cryogenic system cost with the shorter $25 \mathrm{MV}$ per meter main linac is about $20 \%$ more expensive than the cryogenic system cost for the longer linac with a gradient of $20 \mathrm{MV}$ per meter.

Table 2. Design heat loads at various temperatures, the equivalent design Refrigeration at $4.5 \mathrm{~K}$, and the input power needed to operate the cryogenic system

\begin{tabular}{|c|c|c|c|c|}
\hline & Main Lina & $20 \mathrm{MV} / \mathrm{m}$ & Main Lina & $25 \mathrm{MV} / \mathrm{m}$ \\
\hline & $\begin{array}{l}\text { Design Load } \\
\text { (W) }\end{array}$ & $\begin{array}{l}\text { Equiv. Refer. } \\
(\mathrm{kW})\end{array}$ & $\begin{array}{l}\text { Design Load } \\
\text { (W) }\end{array}$ & $\begin{array}{l}\text { Equiv. Refer } \\
(\mathrm{kW})\end{array}$ \\
\hline Heat \& Refrigeration at $2.0 \mathrm{~K}$ & 2381.4 & 5.50 & 3437.0 & 7.99 \\
\hline Heat \& Refrigeration at $4.5 \mathrm{~K}$ & 157.1 & 0.16 & 157.1 & 0.16 \\
\hline Heat \& Refrigeration at $5-8 \mathrm{~K}$ & 980.0 & 0.88 & 868.7 & 0.78 \\
\hline Heat \& Refrigeration at $40-80 \mathrm{~K}$ & 24522.7 & $\underline{2.43}$ & 27771.4 & $\underline{2.75}$ \\
\hline Total Equivalent 4.5 K Refrigeration & & 8.97 & & 11.68 \\
\hline Input Power for the Cryogenic System & & MW & & AW \\
\hline Minimum Installed Cooling Capacity & 3.6 & MW & 4.5 & AW \\
\hline
\end{tabular}

The input power to the cold box compressors is to first order proportional to the equivalent refrigeration at $4.5 \mathrm{~K}$. The longer linac is slightly more efficient than the smaller. In both cases, the efficiency assumed is about 22 percent of Carnot (without liquid nitrogen pre-cooling). Given the recent experience with machines at DESY and CERN one might expect actual machine efficiencies to approach 30 percent of Carnot. Roughly half of the cold box inefficiencies are in the helium compressors.

\section{Concluding Comments}

With modifications the TESLA cryogenic module can be used for $\mathrm{CW}$ operations at gradients up to $25 \mathrm{MV}$ per meter. It appears that the required modifications are feasible and fit within the existing TESLA design cryogenic module vacuum vessel.

The refrigeration plant needed to cool the cavities and undulator magnets is similar in size to one of the three existing HERA cryogenic plants at DESY. The technology for such plants is well understood and there are at least two reliable vendors who can produce the cryogenic plant. The rest of the cryogenic system is understood well enough to allow a cost estimate to be made. The cryogenic system also fits within the parameter space of cryogenic systems that have been built at other locations. 
The choice of acceleration gradient in the linac cavities does have an impact on the cost and the operating margin for the cryogenics system, and it appears that a lower acceleration gradient linac may be the more cost-effective option.

\section{Acknowledgements}

The author wishes to thank D. Proch, S. Wolff, and B. Peterson of DESY for their candid comments concerning the superconducting RF cavity cooling system for CW operations. This work was supported by the Office of Science, United States Department of Energy under DOE contract number DE-AC03-76SF00098

\section{References}

[1] “TESLA Technical Design Report,” DESY 20010011, March 2001

[2] S. Wolff DESY, private commination July 2002

[3] J. L. Smith Jr. and G. Robinson, "A Tribute to Samuel C. Collins: September 28, 1898 - June 19, 1984," Advances in Cryogenic Engineering 31, p 1, Plenum Press, New York (1985). On page 6, this paper references the first closed cycle $1.8 \mathrm{~K}$ helium refrigerator ever built by Sam Collins. The report refers to a cold compressor designed by Sam Collins in 1967. The notes were never published and the compressor was never built.

[4] G. M. Gistau, G. Claudet, "The Tore Supra 300 W - 1.75 K Refrigerator," Advances in Cryogenic Engineering 31, p 607, Plenum Press, New York, (1985)

[5] J. Fuerst, "Selection of Cold Compressors for the Fermilab Tevetron," Advances in Cryogenic Engineering 39, p 863, Plenum Press, New York (1993)

[6] R. A. Byrns and M. A. Green, "An Update on Estimating the Cost of Cryogenic Refrigeration," co-authored R. Byrns, Advances in Cryogenic Engineering 43, p 1661, Plenum Press, (1997), LBNL-40188 


\section{DISCLAIMER}

This document was prepared as an account of work sponsored by the United States Government.

While this document is believed to contain correct information, neither the United States Government nor any agency thereof, nor The Regents of the University of California, nor any of their employees, makes any warranty, express or implied, or assumes any legal responsibility for the accuracy, completeness, or usefulness of any information, apparatus, product, or process disclosed, or represents that its use would not infringe privately owned rights. Reference herein to any specific commercial product, process, or service by its trade name, trademark, manufacturer, or otherwise, does not necessarily constitute or imply its endorsement, recommendation, or favoring by the United States Government or any agency thereof, or The Regents of the University of California. The views and opinions of authors expressed herein do not necessarily state or reflect those of the United States Government or any agency thereof, or The Regents of the University of California.

Ernest Orlando Lawrence Berkeley National Laboratory is an equal opportunity employer. 